\title{
ZONAS HOMOGÊNEAS DE ATRIBUTOS DO SOLO PARA O MANEJO DE IRRIGAÇÃO EM POMAR DE VIDEIRA ${ }^{(1)}$
}

\author{
Patricia dos Santos Nascimento ${ }^{(2)}$, Juliano Athayde Silva ${ }^{(3)}$, Bruno Ricardo Silva Costa ${ }^{(3)}$ \\ \& Luís Henrique Bassoi ${ }^{(4)}$
}

RESUMO

$\mathrm{Na}$ análise das variabilidades espacial e temporal dos fatores inerentes à produtividade agrícola, a geoestatística constitui a base para a aplicação dos conceitos de agricultura de precisão. Assim, este estudo foi desenvolvido com os objetivos de avaliar a variabilidade espacial de atributos físico-hídricos do solo e delimitar zonas homogêneas para o manejo da irrigação em um cultivo de videira, utilizando ferramentas geoestatísticas. Um experimento de campo foi realizado em Petrolina, PE, no Vale do Submédio São Francisco, em um pomar de videira irrigada por microaspersão. Em uma área de 3,2 ha, foram coletadas 160 amostras de solo nas camadas de 0,0-0,20 e 0,20-0,40 m, em quatro transeções, as quais foram utilizadas para as determinações das frações granulométricas (areia total, silte e argila), curva de retenção de água no solo, densidade do solo e porosidade total do solo. Os dados foram submetidos às análises pela estatística descritiva e geoestatística. A variabilidade espacial dos atributos físico-hídricos do solo foi observada; foi realizada a interpolação por krigagem e geração de mapas de contorno para a delimitação de zonas homogêneas. Os atributos de solo analisados apresentaram baixa (densidade do solo, porosidade total e areia total) e média heterogeneidade (silte e argila). $O$ índice de dependência espacial observado foi classificado entre moderado e forte para todos os atributos. A água disponível na camada de 0,2-0,4 $\mathrm{m}$ apresentou $\mathrm{o}$ maior alcance $\mathrm{e}$ foi considerada $\mathrm{o}$ atributo para delimitação de três zonas homogêneas, que receberam diferentes volumes de água de irrigação durante dois ciclos de produção da videira, em razão da umidade do solo medido em cada uma dessas zonas.

Termos de indexação: água disponível no solo, geoestatística, dependência espacial.

(1) Parte da Tese de Doutorado do primeiro autor apresentada ao PPG em Agronomia (Irrigação e Drenagem) da Faculdade de Ciências Agronômicas da Universidade Estadual Paulista "Júlio de Mesquita Filho" - FCA/UNESP. Recebido para publicação em 26 de setembro de 2013 e aprovado em 7 de maio de 2014.

(2) Doutora em Agronomia (Irrigação e Drenagem), FCA/UNESP. Fazenda Experimental Lageado. Caixa Postal 237. CEP 18610307 Botucatu (SP). E-mail: patyysn@yahoo.com.br

(3) Mestrando em Engenharia Agrícola, Universidade Federal do Vale do São Francisco - UNIVASF, Campus de Juazeiro. Av. Antônio Carlos Magalhães, 510, Country Club. CEP 48902-300 Juazeiro (BA). E-mail: julianoathayde@hotmail.com, bruno.ricardo.silva@hotmail.com

(4) Pesquisador, Empresa Brasileira de Pesquisa Agropecuária - EMBRAPA/CPATSA. Caixa Postal 23. CEP 56302-970 Petrolina (PE). E-mail: luis.bassoi@embrapa.br 


\title{
SUMMARY: HOMOGENEOUS ZONES OF SOIL PROPERTIES FOR IRRIGATION MANAGEMENT IN A VINEYARD
}

\begin{abstract}
In analysis of the spatial and temporal variability of the factors inherent to agricultural production, geostatistics is the basis for the application of the concepts of precision agriculture. Thus, this study was developed to evaluate the spatial variability of soil physical and water properties and to delineate homogeneous zones in a vineyard using geostatistical tools. A field experiment was carried out in Petrolina, Pernambuco, Brazil (in the Lower Middle São Francisco Valley) in a grape vineyard, irrigated by microsprinklers. In a 3.2 ha area, 160 soil samples were collected in the 0.0-0.20 and 0.20-0.40 m layers, in four transects, which were used for determination of soil particle size fractions (total sand, silt, and clay), the soil water retention curve, soil bulk density, and total porosity. Data were subjected to descriptive statistical analysis and geostatistical analysis, and spatial variability of the physical and water properties were observed. Interpolation by kriging was then performed, and contour maps were generated to delimit homogeneous soil zones. Soil bulk density, total porosity, and total sand showed low heterogeneity, while silt and clay showed medium heterogeneity. The spatial dependence index observed was classified from moderate to strong for all properties. The water available in the 0.20-0.40 $\mathrm{m}$ soil layer showed the greatest range, and it was the property considered for delimitation of three homogeneous zones, which received different amounts of irrigation water throughout two growing seasons in accordance with the soil moisture measured in each one of these zones.
\end{abstract}

Index terms: available soil water, geostatistics, spatial dependence.

\section{INTRODUÇÃO}

Um das particularidades da agricultura está no tratamento adotado para o manejo das áreas agrícolas, o qual considera a área de produção de forma homogênea, desconsiderando, assim, a variabilidade natural que ocorre nas áreas de produção. Tais técnicas conduzem a práticas agrícolas com base nas médias observadas dentro da área de cultivo, tornando o manejo realizado homogêneo em toda a área, o qual eventualmente irá atender apenas as necessidades médias das culturas, submetendo essas a situações de super ou subestimação de suas reais necessidades.

Segundo Dellamea et al. (2007), a agricultura de precisão (AP) permite identificar a variabilidade existente na área e a partir disso investigar fatores limitantes (físicos, químicos e biológicos), além de propor alternativas de manejo diferenciadas de acordo com a necessidade de cada área. Caracterizada pela elevada quantidade de informações disponibilizadas, a AP pode contribuir para o estabelecimento de relações espaciais de atributos de solo com a produtividade das culturas (Amado \& Giotto, 2009).

Nos últimos anos, a geoestatística efetivou-se no auxílio do melhor entendimento da variabilidade espacial de diversos parâmetros de interesse nas Ciências Agrárias, permitindo a interpretação de dados com base na estrutura de sua variabilidade natural, considerando a dependência espacial na área a ser estudada (Batista \& Zimback, 2010).

$\mathrm{O}$ conhecimento das variabilidades espacial e temporal dos fatores inerentes à produtividade agrícola do solo constitui uma informação de extrema relevância para a tomada de decisão quanto às práticas de manejo a serem adotadas em sistemas de produção agrícola. A análise de mapas sequenciais de produtividade possibilitou a Molin (2002) definir unidades de gerenciamento. Entretanto, as variabilidades observadas a partir dos mapas de produção constituem apenas uma etapa de todo o processo que envolve a AP e representa o efeito combinado de diversas fontes de variabilidades espacial e temporal (Alcântara, 2010). Além dos mapas de produtividade, alguns atributos que influem de forma direta ou indireta na variabilidade da produção vêm sendo estudados como possíveis indicativos para a determinação de unidades de gerenciamento agrícola.

De acordo com Machado et al. (2006), com o aperfeiçoamento dos computadores, o surgimento dos sistemas de posicionamento global (GPS) e dos programas geoestatísticos, o mapeamento de determinados atributos passou a ser factível, o que tornou possível a obtenção de mapas de colheita e o estabelecimento de zonas de manejo do solo ou da planta.

Segundo Coelho Filho et al. (2001), a utilização da descrição espacial das variáveis mais importantes no manejo da irrigação auxilia o manejo mais racional de água na área, e o controle local pode ser realizado após a subdivisão da área, em zonas mais homogêneas. Assim, os objetivos deste trabalho foram avaliar a variabilidade espacial de atributos físico-hídricos do solo em um pomar de videira irrigada em Petrolina, $\mathrm{PE}$, delimitar zonas homogêneas de solo para fins de manejo de irrigação e diferenciar a lâmina de irrigação, levando-se em conta a umidade do solo presente em cada zona. 


\section{MATERIAL E MÉTODOS}

O estudo foi realizado em Petrolina, PE, no Vale do Submédio São Francisco, no lote 180 do Perímetro Irrigado Senador Nilo Coelho, Núcleo 5 (latitude S $9^{\circ} 23^{\prime} 12,8^{\prime \prime}$, longitude W $40^{\circ} 38^{\prime} 13,8^{\prime \prime}$, altitude $394 \mathrm{~m}$ ). O solo foi classificado como Neossolo Quartzarênico (Embrapa, 2006), o qual é caracterizado como profundo, não hidromórfico, de textura arenosa (classes texturais areia e areia franca), com permeabilidade rápida ao longo de todo o perfil e destituído de minerais primários facilmente intemperizáveis (Curi et al., 1993).

Para a realização do estudo, foi selecionado um pomar de videira cv. Thompson Seedless sobre o portaenxerto SO4, com 40 fileiras de plantas e 82 plantas por fileira, plantadas em maio de 2004 no espaçamento de $4 \times 2,5 \mathrm{~m}$, irrigadas por microaspersão, com um difusor por planta com vazão aferida de $30 \mathrm{~L} \mathrm{~h}^{-1} \mathrm{e} \mathrm{com}$ plantas conduzidas no sistema de latada. Para avaliar a variabilidade espacial de atributos físico-hídricos do solo, bem como a delimitação de zonas homogêneas para o manejo, foram coletadas amostras deformadas de solo nas camadas de 0,0-0,20 e 0,20-0,40 m, em quatro transeções (fileiras 5, 15, 25 e 35). Em cada fileira, as amostras foram coletadas na linha de plantas, a cada $5 \mathrm{~m}$, totalizando 40 amostras por fileira de plantas e camada avaliada, e 160 amostras para toda a área (Figura 1). As fileiras e as plantas em cada fileira eram numeradas, o que viabilizou o referenciamento das videiras. Quatro válvulas derivavam a água de irrigação para a área, sendo uma para cada 10 fileiras. Por iniciativa do próprio produtor, foram instalados registros de linha nas mangueiras de polietileno de cada fileira, entre as videiras 22 e 23 e 62 e 63 , para que a aplicação de água pudesse ser dividida em três partes ou terços da área (Figura 1). Tal iniciativa foi tomada com base na constatação visual da existência de áreas que apresentavam drenagem mais ou menos lenta.

As amostras foram utilizadas para a determinação das frações granulométricas areia total, silte e argila ( $\mathrm{kg} \mathrm{kg}^{-1}$ ), de acordo com Embrapa (1997), e para obtenção da curva de retenção de água no solo pelo método da centrífuga (Silva \& Azevedo, 2002), sendo considerados a capacidade de campo $\left(\theta_{\mathrm{cc}}, \mathrm{m}^{3} \mathrm{~m}^{-3}\right)$, e o ponto de murcha permanente $\left(\theta_{\mathrm{pmp}}, \mathrm{m}^{3} \mathrm{~m}^{-3}\right)$ os valores de umidade do solo retida a 0,006 e 1,5 MPa. A água disponível $(\mathrm{AD}, \mathrm{mm})$ foi obtida a partir da diferença entre $\theta_{c c}$ e $\theta_{\text {pmp }}$, em cada camada de solo analisada e multiplicada pela sua espessura. Também foram coletadas, com anel cilíndrico de volume conhecido $\left(\mathrm{V}_{\mathrm{a}}, \mathrm{m}^{3}\right)$, amostras indeformadas de solo, as quais foram secas em estufa a $105{ }^{\circ} \mathrm{C}$, durante $48 \mathrm{~h}$, para determinação de sua massa seca $\left(\mathrm{m}_{\mathrm{s}}, \mathrm{kg}\right)$. A relação entre $m_{\mathrm{s}}$ e $V_{\mathrm{a}}$ permitiu a obtenção da densidade do solo (Ds, $\mathrm{kg} \mathrm{m}^{-3}$ ); já a relação entre Ds e a densidade das partículas ( $\left.\mathrm{Dp}, \mathrm{kg} \mathrm{m}^{-3}\right)$, também determinada conforme Embrapa (1997), a obtenção da porosidade total do solo $\left(\mathrm{PT}, \mathrm{m}^{3} \mathrm{~m}^{-3}\right)$.

A análise descritiva dos dados determinou a média, a mediana (med), o desvio-padrão (s), o valor mínimo (mín), o valor máximo (máx), o coeficiente de variação (CV, \%), o coeficiente de assimetria (Cs) e o coeficiente

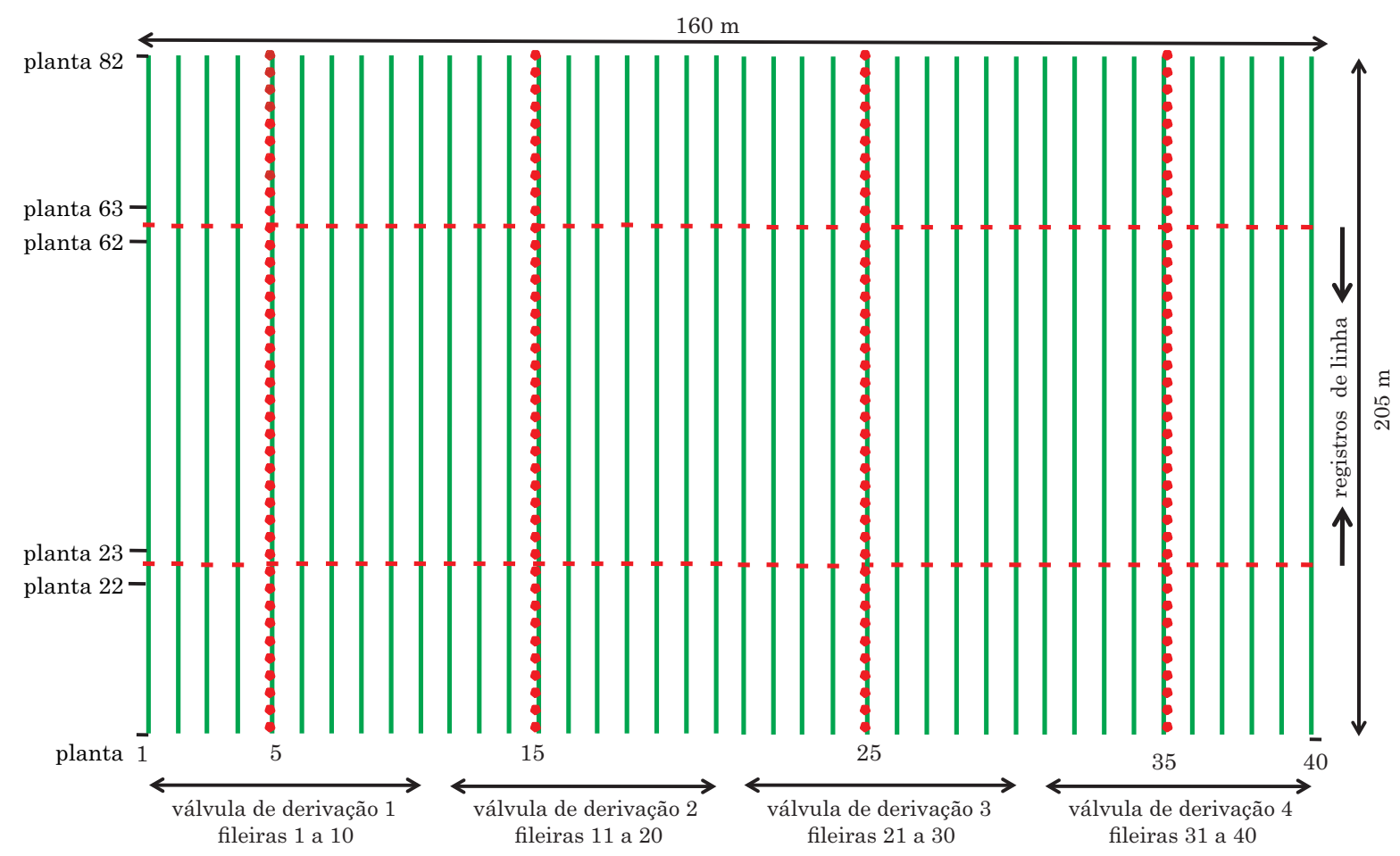

Figura 1. Croqui com as transeções (fileiras 5, 15, 25 e 35) para coleta de solo nas camadas de 0-0,2 e 0,2-0,4 m. 
de curtose (Ck), usando o programa Statistica 5.0 (Statsoft, 1999). A hipótese da normalidade dos dados foi testada pelos testes de Kolmogorov-Smirnov (K-S) a $5 \%$, proposto por Campos (1979). Cada atributo do solo estudado foi analisado pelo programa GS+, versão 7.0 (Robertson, 1998), em que foram obtidos os variogramas experimentais utilizados na determinação da variabilidade e dependência espacial entre as amostras, representando quantitativamente a variação de um fenômeno. Para o ajuste dos variogramas experimentais, foram testados três modelos teóricos (esférico, exponencial e gaussiano), considerados adequados aos dados em análise (Faraco et al., 2008). Realizou-se a escolha do modelo, observando os patamares mais claros e definidos e os menores erros (Cajazeira \& Assis Júnior, 2011). Uma vez ajustado um modelo matemático ao variograma, utilizou-se a técnica de krigagem ordinária para realizar a interpolação dos dados para os locais não amostrados sem tendência e com variância mínima (Vieira, 2000; Carvalho \& Assad, 2005; Grego \& Vieira, 2005). A utilização da técnica de krigagem utiliza a dependência espacial entre amostras vizinhas, expressa no variograma para estimar valores em qualquer posição dentro do campo (Vieira, 2000). Para a construção dos mapas de isolinhas (zonas homogêneas) dos atributos avaliados, foi utilizado o programa Surfer 7.0 (Golden Software, 1999), o qual usou para tanto os valores estimados por meio da técnica de krigagem para os locais não amostrados (Vieira \& Paz González, 2003). O índice de dependência espacial (IDE) dos atributos, que é dado por $[\mathrm{C} /(\mathrm{C} 0+$ C) $] \times 100 \%$, foi determinado e classificado, segundo Zimback (2001), como baixo (IDE < $25 \%$ ), moderado $(25 \%<$ IDE $<75 \%)$ e forte (IDE $>75 \%)$.

Tensiômetros de punção digital foram instalados a 0,20 e 0,40 m de profundidade em cada uma das zonas homogêneas do solo estabelecidas, para determinar o potencial matricial da água e a correspondente umidade do solo, por meio da curva de retenção da água no solo.

Durante dois ciclos consecutivos de produção (18 de abril a 5 de agosto de 2011 e 19 de março a 7 de julho de 2012), a lâmina de irrigação foi calculada com base na evapotranspiração da cultura (ETc, $\mathrm{mm}$ ), obtida pelo produto entre a evapotranspiração de referência (ETo, mm) estimada por uma estação agrometeorológica automática instalada no local e o coeficiente de cultura (kc) para cada estádio fenológico da videira. Essa lâmina era então ajustada para cada uma das zonas de manejo estabelecidas, com base na umidade do solo determinada pela tensiometria, para evitar uma aplicação de água excessiva, acima da capacidade de campo.

A produção da videira em ambos os ciclos foi estimada pela contagem de cachos de uvas por planta, em toda a área. Os dados também foram analisados pela estatística descritiva e geoestatística para a verificação da homogeneidade da produção.

\section{RESULTADOS E DISCUSSÃO}

No quadro 1, apresenta-se a estatística descritiva dos atributos avaliados para as camadas de 0,0-0,20 e 0,20-0,40 m. Os parâmetros, em sua maioria, evidenciam simetria e curtose compatíveis com a distribuição normal (valores próximos de 0,0), assim como a proximidade entre os valores de média e mediana sugerem a distribuição simétrica dos dados analisados. A distribuição normal para características de solo também é relatada por outros pesquisadores (Carvalho et al., 2003; Souza et al., 2004; Lima et al., 2006; Campos et al., 2007). A hipótese da normalidade pode ser confirmada com o teste de aderência à normalidade, de Kolmogorov-Smirnov, o qual mede a distância máxima entre os resultados de uma distribuição a ser testada e os resultados associados à distribuição hipoteticamente verdadeira (Ortiz, 2003). Com exceção da PT e do silte na camada de 0,0-0,20 m, observou-se que os atributos em ambas as camadas apresentam distribuição normal a $5 \%$ de significância.

De acordo com Pimentel-Gomes \& Garcia (2002), a variabilidade de um atributo pode ser classificada de acordo com a magnitude do seu coeficiente de variação $(\mathrm{CV})$. Ao analisar o $\mathrm{CV}$, segundo a classificação proposta por Warrick \& Nielsen (1980), notou-se que os atributos Ds, PT e areia total apresentaram baixa variabilidade $(\mathrm{CV}<12 \%)$ em ambas as camadas avaliadas, revelando assim a baixa heterogeneidade desses atributos na área. Características similares foram observadas por Santos et al. (2012). O silte e a argila demonstraram uma variação considerada como média $(12<\mathrm{CV}<60 \%)$ para as camadas avaliadas, corroborando assim com as observações feitas por Sousa et al. (1999) e Eguchi et al. (2002).

A observação da variabilidade de atributos do solo com base nos parâmetros disponíveis pela estatística descritiva permite o conhecimento sobre a normalidade dos dados. Entretanto, apresenta limitações quanto à distribuição espacial dos dados, não permitindo, desse modo, que se chegue a conclusões sobre a relação entre a variação dos dados e os locais de amostragem (Mendes et al., 2008). Para Souza (1999), o desviopadrão e o CV dão uma ideia da magnitude de variabilidade de atributos químicos e físicos dos solos; porém, esse autor nada informa quanto à dependência espacial desses atributos, o que só é possível por meio de técnicas geoestatísticas.

No quadro 2 e na figura 2, estão apresentados os resultados referentes ao ajuste dos semivariogramas dos atributos Ds, PT, AT, silte e argila nas camadas de 0,0-0,20 e 0,20-0,40 m. Em ambas as camadas avaliadas, os valores de IDE observados variaram de moderado a forte, indicando assim a dependência dos atributos estudados. Ao avaliar a variabilidade em um Latossolo Amarelo distrófico, com textura francoarenosa, Zucoloto et al. (2011) observaram moderada dependência espacial para atributos físicos do solo. De 
Quadro 1. Estatística descritiva dos atributos densidade do solo (Ds), porosidade total (PT), areia total (AT), silte e argila, nas camadas de 0,0-0,20 e 0,20-0,40 m

\begin{tabular}{lccccccccc}
\hline Atributo & Média & Med & s & Mín & Máx & CV & Cs & Ck & $\mathbf{d}^{(1)}$ \\
\hline & & & & & & & $\%$ & & \\
& & & & & $0,0-0,20 \mathrm{~m}$ & & & & \\
& & & & & & & \\
Ds $\left(\mathrm{kg} \mathrm{dm}^{-3}\right)$ & 1,370 & 1,374 & 0,076 & 1,172 & 1,504 & 5,50 & $-0,32$ & $-0,47$ & $0,06^{\mathrm{ns}}$ \\
PT $\left(\mathrm{m}^{3} \mathrm{~m}^{-3}\right)$ & 0,449 & 0,451 & 0,029 & 0,404 & 0,536 & 6,38 & 0,14 & $-0,73$ & $0,08^{*}$ \\
AT $\left(\mathrm{kg} \mathrm{kg}^{-1}\right)$ & 0,834 & 0,837 & 0,029 & 0,741 & 0,900 & 3,60 & $-0,50$ & 0,74 & $0,06^{\mathrm{ns}}$ \\
Silte $\left(\mathrm{kg} \mathrm{kg}^{-1}\right)$ & 0,118 & 0,113 & 0,034 & 0,049 & 0,229 & 28,0 & 0,65 & 0,44 & $0,08^{*}$ \\
Argila $\left(\mathrm{kg} \mathrm{kg}^{-1}\right)$ & 0,048 & 0,047 & 0,014 & 0,002 & 0,093 & 31,5 & $-0,11$ & $-0,09$ & $0,04^{\mathrm{ns}}$ \\
& & & & & $0,20-0,40 \mathrm{~m}$ & & & & \\
Ds $\left(\mathrm{kg} \mathrm{dm}^{-3}\right)$ & 1,420 & 1,420 & 0,063 & 1,228 & 1,532 & 4,40 & $-0,22$ & $-0,56$ & $0,06^{\mathrm{ns}}$ \\
PT $\left(\mathrm{m}^{3} \mathrm{~m}^{-3}\right)$ & 0,449 & 0,451 & 0,031 & 0,250 & 0,551 & 7,00 & $-1,26$ & 9,03 & $0,06^{\mathrm{ns}}$ \\
AT $\left(\mathrm{kg} \mathrm{kg}^{-1}\right)$ & 0,860 & 0,858 & 0,028 & 0,752 & 0,946 & 3,40 & $-0,04$ & 1,07 & $0,04^{\mathrm{ns}}$ \\
Silte $\left(\mathrm{kg} \mathrm{kg}^{-1}\right)$ & 0,081 & 0,081 & 0,032 & 0,011 & 0,187 & 40,0 & 0,33 & 0,11 & $0,05^{\mathrm{ns}}$ \\
Argila $\left(\mathrm{kg} \mathrm{kg}^{-1}\right)$ & 0,059 & 0,057 & 0,018 & 0,011 & 0,098 & 31,8 & $-0,07$ & $-0,52$ & $0,04^{\mathrm{ns}}$ \\
\hline
\end{tabular}

(1) $\mathrm{d}$ : teste de normalidade (Kolmogorov-Smirnov), ns e *: não significativo e significativo a 5 \%, respectivamente. Med: mediana; s: desvio-padrão; Mín: valor mínimo; Máx: valor máximo; CV: coeficiente de variação; Cs: coeficiente de assimetria; e Ck: coeficiente de curtose.

Quadro 2. Parâmetros do variograma dos atributos densidade do solo (Ds), porosidade total (PT), areia total (AT), silte e argila, nas camadas de 0,0-0,20 e 0,20-0,40 m

\begin{tabular}{|c|c|c|c|c|c|}
\hline Parâmetro & Modelo & Alcance & $\mathrm{C}_{0}$ & $\mathrm{C}_{0}+\mathrm{C}$ & IDE \\
\hline & & $\mathrm{m}$ & & & $\%$ \\
\hline & \multicolumn{5}{|c|}{$0,0-0,20 \mathrm{~m}$} \\
\hline Ds $\left(\mathrm{kg} \mathrm{dm}^{-3}\right)$ & Gausiano & 98,90 & $1,42.10^{-3}$ & $7,14.10^{-3}$ & 80,93 \\
\hline $\mathrm{PT}\left(\mathrm{m}^{3} \mathrm{~m}^{-3}\right)$ & Gaussiano & 102,71 & $0,2,1.10^{-3}$ & $1,11.10^{-3}$ & 81,20 \\
\hline $\mathrm{AT}\left(\mathrm{kg} \mathrm{kg}^{-1}\right)$ & Esférico & 62,70 & $0,34 \cdot 10^{-3}$ & $9,50.10^{-3}$ & 62,65 \\
\hline Silte $\left(\mathrm{kg} \mathrm{kg}^{-1}\right)$ & Esférico & 56,90 & $0,40.10^{-3}$ & $1,22.10^{-3}$ & 66,27 \\
\hline Argila $\left(\mathrm{kg} \mathrm{kg}^{-1}\right)$ & Esférico & 66,70 & $0,50.10^{-4}$ & $0,2,2.10^{-3}$ & 76,42 \\
\hline \multicolumn{6}{|c|}{$0,20-0,40 \mathrm{~m}$} \\
\hline Ds $\left(\mathrm{kg} \mathrm{dm}^{-3}\right)$ & Gausiano & 109,10 & $1,81.10^{-3}$ & $4,53.10^{-3}$ & 60,23 \\
\hline $\mathrm{PT}\left(\mathrm{m}^{3} \mathrm{~m}^{-3}\right)$ & Gausiano & 130,12 & $0,38 \cdot 10^{-3}$ & $0,93 \cdot 10^{-3}$ & 66,20 \\
\hline $\mathrm{AT}\left(\mathrm{kg} \mathrm{kg}^{-1}\right)$ & Esférico & 85,80 & $0,45.10^{-3}$ & $0,96 \cdot 10^{-3}$ & 54,06 \\
\hline Silte $\left(\mathrm{kg} \mathrm{kg}^{-1}\right)$ & Esférico & 71,70 & $0,54 \cdot 10^{-3}$ & $1,14.10^{-3}$ & 52,00 \\
\hline Argila $\left(\mathrm{kg} \mathrm{kg}^{-1}\right)$ & Esférico & 42,50 & $0,70.10^{-4}$ & $0,33.10^{-3}$ & 77,19 \\
\hline
\end{tabular}

$\mathrm{C}_{0}$ : efeito pepita; $\mathrm{C}_{0}+\mathrm{C}$ : patamar; e IDE: índice de dependência espacial.

maneira geral, os atributos físicos do solo desse estudo apresentaram dependência espacial ajustada ao modelo esférico, reafirmando assim o comportamento já relatado por Vieira (1997), Carvalho et al. (2002), Cajazeira \& Assis Júnior (2011) e Carvalho et al. (2003). Exceções foram observadas para os atributos Ds e PT, em ambas as camadas avaliadas, os quais obtiveram o melhor ajuste ao modelo gaussiano (Quadro 2, Figura 2). Na camada de 0,0-0,20 m, os atributos Ds, PT e argila apresentaram os maiores IDE, respectivamente, 80, 81 e $76 \%$, indicando forte dependência espacial, com alcances de 98,90; 102,71; e $66,70 \mathrm{~m}$. O menor alcance foi observado para o atributo argila na camada de $0,20-0,40 \mathrm{~m}$. A variabilidade dos atributos do solo pode ser atribuída a fatores intrínsecos ou extrínsecos; no primeiro caso, predominam os fatores relacionados à formação do solo (mineralogia, textura), enquanto, no segundo, estão mais relacionados com as práticas de manejo adotadas. Geralmente, uma forte dependência espacial dos atributos do solo é atribuída aos fatores intrínsecos; aos extrínsecos, uma fraca dependência (Cambardella et al.,1994; Carvalho et al., 2003).

O conhecimento do alcance da dependência espacial permite o delineamento de futuras amostragens, assegurando as mesmas condições do estudo em questão. Assim, ao serem realizadas determinações a distâncias maiores que o alcance, os dados têm 
distribuição espacial aleatória e, por isso, são independentes entre si, podendo ser aplicada a estatística clássica, enquanto as determinações realizadas em distâncias menores que o alcance são correlacionadas umas as outras, permitindo que se façam interpolações para espaçamentos menores que os amostrados (Carvalho et al., 2003).

0,0-0,20 m
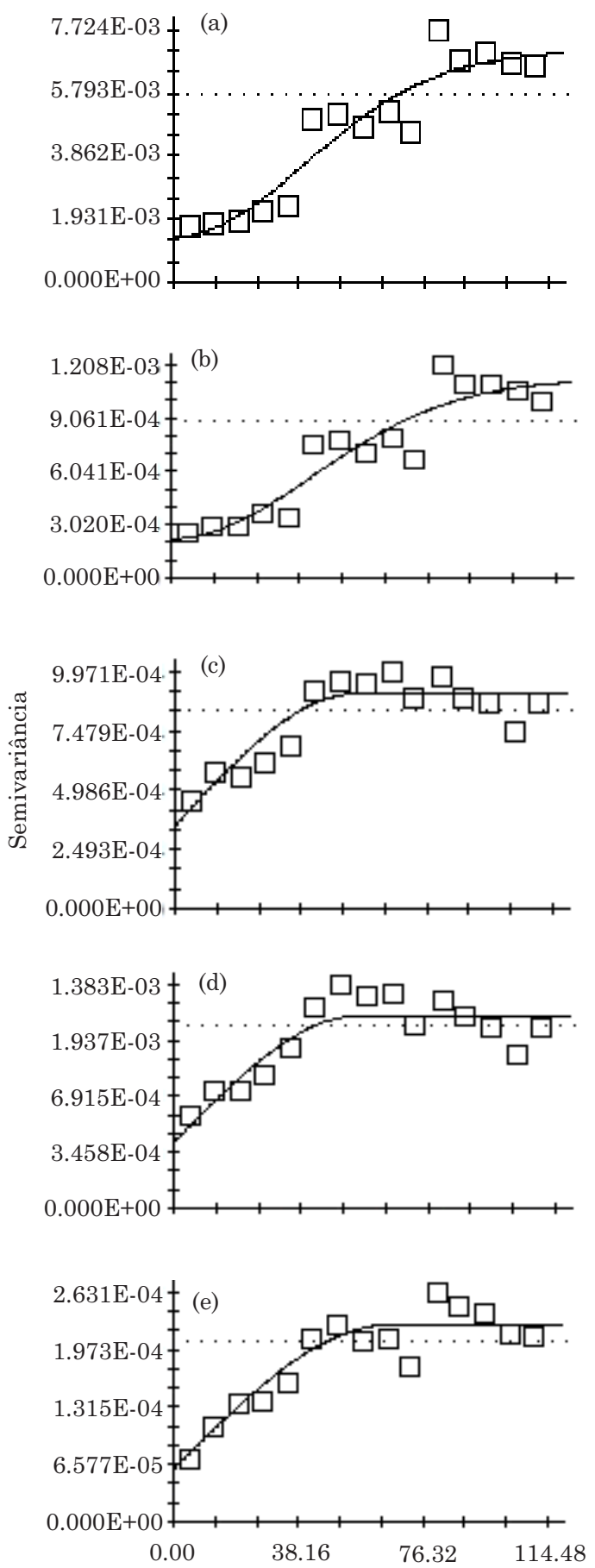

No quadro 3, encontra-se o resumo estatístico da umidade do solo em cada uma das tensões aplicadas e da água disponível, para cada camada. Na camada de 0,0-0,20 m, observou-se distribuição normal para os dados avaliados a $5 \%$ de significância, com exceção da umidade na tensão de $0,1 \mathrm{MPa}$. Já na camada de 0,20-0,40 m, a distribuição normal dos dados só foi
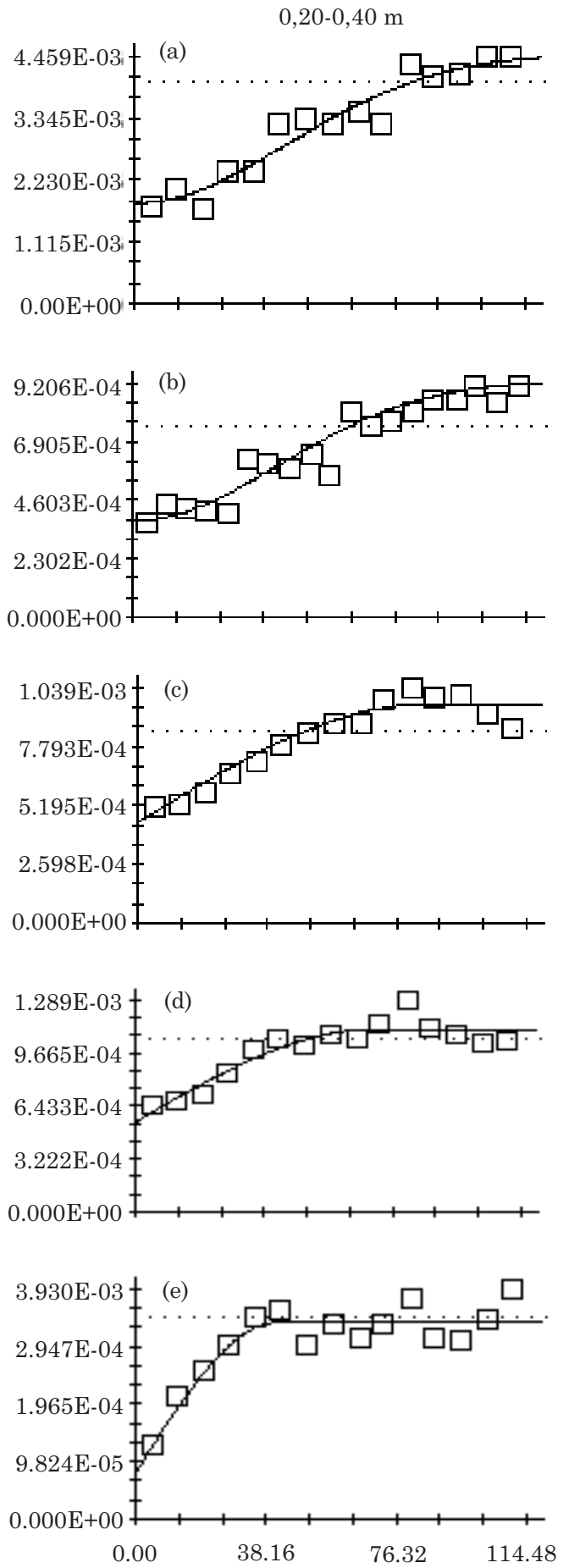

Distância, m

Figura 2. Semivariograma dos atributos densidade do solo (a), porosidade total (b), areia total (c), silte (d) e argila (e), nas camadas de 0,0-0,20 m e 0,20-0,40 m. 
Quadro 3. Estatística descritiva da umidade do solo ( $($ ), em cada tensão aplicada, e da água disponível (AD), nas camadas de $0,0-0,20$ e $0,20-0,40 \mathrm{~m}$

\begin{tabular}{|c|c|c|c|c|c|c|c|c|c|}
\hline Umidade do solo/Tensão & Média & Med & $\mathrm{s}$ & Mín & Máx & $\mathrm{CV}$ & $\mathrm{Cs}$ & $\mathbf{C k}$ & $d^{(1)}$ \\
\hline \multirow[t]{2}{*}{$\mathrm{m}^{3} \mathrm{~m}^{-3} / \mathrm{MPa}$} & & & & & & $\%$ & & & \\
\hline & \multicolumn{9}{|c|}{$0,0-0,20 \mathrm{~m}$} \\
\hline ө 0,006 & 0,177 & 0,176 & 0,021 & 0,128 & 0,252 & 12,05 & 0,32 & 0,35 & $0,06^{\mathrm{ns}}$ \\
\hline ө 0,010 & 0,140 & 0,139 & 0,018 & 0,104 & 0,225 & 13,05 & 0,87 & 2,58 & $0,05^{\mathrm{ns}}$ \\
\hline ө 0,033 & 0,119 & 0,118 & 0,015 & 0,087 & 0,170 & 12,84 & 0,37 & $-0,12$ & $0,06^{\mathrm{ns}}$ \\
\hline ө 0,06 & 0,110 & 0,109 & 0,014 & 0,081 & 0,160 & 13,21 & 0,47 & 0,20 & $0,05^{\mathrm{ns}}$ \\
\hline$\Theta 0,1$ & 0,104 & 0,102 & 0,015 & 0,076 & 0,188 & 14,88 & 1,23 & 4,69 & 0,08 * \\
\hline$\Theta 1,5$ & 0,084 & 0,083 & 0,013 & 0,052 & 0,133 & 15,82 & 0,32 & 0,65 & $0,04^{\mathrm{ns}}$ \\
\hline \multirow[t]{2}{*}{$\mathrm{AD}(\mathrm{mm})$} & 0,093 & 0,092 & 0,015 & 0,055 & 0,149 & 17,00 & 0,56 & 0,39 & $0,06^{\mathrm{ns}}$ \\
\hline & \multicolumn{9}{|c|}{$0,20-0,40 \mathrm{~m}$} \\
\hline ө 0,006 & 0,149 & 0,146 & 0,027 & 0,084 & 0,251 & 18,11 & 0,69 & 1,21 & $0,05^{\mathrm{ns}}$ \\
\hline ө 0,010 & 0,114 & 0,113 & 0,021 & 0,070 & 0,220 & 18,59 & 1,18 & 3,89 & $0,09^{*}$ \\
\hline ө 0,033 & 0,094 & 0,092 & 0,019 & 0,060 & 0,203 & 19,99 & 1,78 & 7,17 & $0,09^{*}$ \\
\hline$\Theta 0,06$ & 0,085 & 0,083 & 0,018 & 0,053 & 0,200 & 21,61 & 2,15 & 9,56 & $0,11^{*}$ \\
\hline$\Theta 0,1$ & 0,080 & 0,077 & 0,018 & 0,047 & 0,199 & 22,54 & 2,48 & 12,62 & $0,13^{*}$ \\
\hline$\Theta 1,5$ & 0,063 & 0,061 & 0,014 & 0,033 & 0,125 & 22,25 & 1,10 & 3,55 & $0,06^{\mathrm{ns}}$ \\
\hline $\mathrm{AD}(\mathrm{mm})$ & 0,086 & 0,084 & 0,018 & 0,030 & 0,184 & 21,38 & 1,20 & 4,82 & $0,07^{*}$ \\
\hline
\end{tabular}

(1) d: teste de normalidade (Kolmogorov-Smirnov), ns e *: não significativo e significativo a 5 \%, respectivamente. Med: mediana; s: desvio-padrão; Mín: valor mínimo; Máx: valor máximo; CV: coeficiente de variação; Cs: coeficiente de assimetria; e Ck: coeficiente de curtose.

observada nas tensões de 0,006 e 1,5 MPa. A camada de $0,0-0,20 \mathrm{~m}$ apresentou umidades superiores para as tensões avaliadas, quando comparada a camada de 0,20-0,40 m. Tal comportamento pode estar associado à maior quantidade de silte verificada na camada superior (Quadro 1). Centurion \& Andrioli (2000) constataram que a retenção de água nas tensões correspondentes à capacidade de campo e ao ponto de murcha permanente evidenciou-se dependente das frações mais finas do solo (silte + argila).

Os coeficientes de variações para a umidade do solo em diferentes tensões e a $\mathrm{AD}$ em ambas as camadas avaliadas foram classificados como sendo médios $(12<\mathrm{CV}<60 \%)$, segundo a classificação proposta por Warrick \& Nielsen (1980). O CV para a $\mathrm{AD}$ na camada de $0,20 \mathrm{~m}$ foi superior ao CV obtido para $\theta_{\mathrm{cc}}$ e $\theta_{\mathrm{pmp}}$, mesmo essas tendo servido de base para a obtenção da AD. Esse fato já foi referendado por Sousa et al. (1999) e Moraes \& Libardi (1993), os quais observaram que o comportamento de uma variável obtida de forma algébrica nem sempre segue o mesmo comportamento das variáveis que lhe deram origem.

A análise dos semivariogramas referentes aos pontos que caracterizaram a curva de retenção de água no solo para a área em estudo nas camadas de $0,0-0,20$ e 0,20-0,40 m possibilitou melhor detalhamento quanto ao comportamento da umidade do solo, quando submetido a diferentes tensões (Quadro 4, Figura 3).
Para a camada de 0,0-0,20 $\mathrm{m}$ e em todas as tensões avaliadas, o modelo que melhor ajustou-se aos dados coletados foi o exponencial, com alcances variando entre 20,10 e 53,40 m. Na camada de 0,20-0,40 m, o ajuste dos dados observados não limitou-se a um único modelo, e os valores de alcance variaram de 55,10 a 113,02 $\mathrm{m}$. Em ambas as camadas avaliadas, o IDE foi classificado como moderado.

A $\mathrm{AD}$ apresentou comportamento distinto nas camadas avaliadas, com ajuste do modelo exponencial na camada 0,0-0,20 m, alcance de $101 \mathrm{~m}$ e um IDE médio, enquanto na camada de 0,20-0,40 m o melhor ajuste foi observado para o modelo gaussiano com alcance de $188 \mathrm{~m}$ e índice de dependência espacial forte.

$\mathrm{Na}$ figura 4, visualiza-se a distribuição espacial dos atributos na área, bem como a delimitação de três zonas homogêneas para fins de manejo. Visualmente, é possível observar forte similaridade na variabilidade espacial da Ds entre as camadas avaliadas. Uma menor semelhança quanto à distribuição espacial foi observada para o atributo PT, sendo possível constatar que áreas com os maiores valores de Ds possuem os menores valores de PT. Tal característica também foi observada por Siqueira et al. (2009), ao estudarem a variabilidade espacial da densidade e da porosidade em um Latossolo. Em relação a AT, silte e argila, não houve um padrão visual de distribuição desses atributos entre as camadas de solo. No mapa referente à argila presente na camada de 0,20-0,40 m, ocorreram 
Quadro 4. Parâmetros do variograma da umidade do solo ( $\Theta$ ) em cada tensão aplicada e da água disponível (AD), nas camadas de 0,0-0,20 e 0,20-0,40 m

\begin{tabular}{|c|c|c|c|c|c|}
\hline Parâmetro & Modelo & Alcance & $\mathbf{C}_{0}$ & $\mathrm{C}_{0}+\mathrm{C}$ & IDE \\
\hline & & $\mathrm{m}$ & & & $\%$ \\
\hline & & & $0,0-0,20 \mathrm{~m}$ & & \\
\hline Ө $0,006\left(\mathrm{~m}^{3} \mathrm{~m}^{-3} / \mathrm{MPa}\right)$ & Exponencial & 48,90 & $0,19 \cdot 10^{-3}$ & $0,43.10^{-3}$ & 55,50 \\
\hline Ө $0,010\left(\mathrm{~m}^{3} \mathrm{~m}^{-3} / \mathrm{MPa}\right)$ & Exponencial & 53,40 & $0,17.10^{-4}$ & $0,35 \cdot 10^{-3}$ & 50,02 \\
\hline Ө $0,033\left(\mathrm{~m}^{3} \mathrm{~m}^{-3} / \mathrm{MPa}\right)$ & Exponencial & 48,12 & $0,12 \cdot 10^{-3}$ & $0,26 \cdot 10^{-3}$ & 57,34 \\
\hline$\Theta 0,06\left(\mathrm{~m}^{3} \mathrm{~m}^{-3} / \mathrm{MPa}\right)$ & Exponencial & 32,33 & $0,80 \cdot 10^{-4}$ & $0,22 \cdot 10^{-3}$ & 60,07 \\
\hline$\Theta 0,1\left(\mathrm{~m}^{3} \mathrm{~m}^{-3} / \mathrm{MPa}\right)$ & Exponencial & 48,80 & $0,12 \cdot 10^{-3}$ & $0,24.10^{-3}$ & 50,20 \\
\hline$\Theta 1,5\left(\mathrm{~m}^{3} \mathrm{~m}^{-3} / \mathrm{MPa}\right)$ & Exponencial & 20,10 & $0,82 \cdot 10^{-3}$ & $0,18 \cdot 10^{-3}$ & 55,00 \\
\hline \multirow[t]{2}{*}{$\mathrm{AD}(\mathrm{mm})$} & Exponencial & 101,40 & $0,80.10^{-4}$ & $0,26 \cdot 10^{-3}$ & 68,88 \\
\hline & & & $0,20-0,40 \mathrm{~m}$ & & \\
\hline Ө $0,006\left(\mathrm{~m}^{3} \mathrm{~m}^{-3} / \mathrm{MPa}\right)$ & Gaussiano & 113,02 & $0,24.10^{-3}$ & $0,64 \cdot 10^{-3}$ & 63,32 \\
\hline Ө $0,010\left(\mathrm{~m}^{3} \mathrm{~m}^{-3} / \mathrm{MPa}\right)$ & Esférico & 110,20 & $0,19 \cdot 10^{-3}$ & $0,40.10^{-3}$ & 51,40 \\
\hline Ө $0,033\left(\mathrm{~m}^{3} \mathrm{~m}^{-3} / \mathrm{MPa}\right)$ & Gaussiano & 75,45 & $0,14 \cdot 10^{-3}$ & $0,28 \cdot 10^{-3}$ & 50,60 \\
\hline$\Theta 0,06\left(\mathrm{~m}^{3} \mathrm{~m}^{-3} / \mathrm{MPa}\right)$ & Gaussiano & 70,40 & $0,12 \cdot 10^{-3}$ & $0,25 \cdot 10^{-3}$ & 50,35 \\
\hline$\Theta 0,1\left(\mathrm{~m}^{3} \mathrm{~m}^{-3} / \mathrm{MPa}\right)$ & Gaussiano & 75,51 & $0,11 \cdot 10^{-3}$ & $0,22 \cdot 10^{-3}$ & 50,20 \\
\hline$\Theta 1,5\left(\mathrm{~m}^{3} \mathrm{~m}^{-3} / \mathrm{MPa}\right)$ & Gaussiano & 55,10 & $0,11.10^{-3}$ & $0,22 \cdot 10^{-3}$ & 47,20 \\
\hline $\mathrm{AD}(\mathrm{mm})$ & Gaussiano & 188,40 & $0,10.10^{-3}$ & $0,41.10^{-3}$ & 76,61 \\
\hline
\end{tabular}

$\mathrm{C}_{0}$ : efeito pepita; $\mathrm{C}_{0}+\mathrm{C}$ : patamar; e IDE: índice de dependência espacial.

pequenas zonas (bull eyes) com valores maiores ou menores desse atributo, tendo ao redor uma área mais extensa com valores intermediários. A observação conjunta dos mapas referentes à textura do solo e Ds não possibilitou a correlação entre áreas com características análogas.

$\mathrm{Na}$ figura 5, apresenta-se a distribuição espacial da umidade do solo nas diferentes tensões e camadas avaliadas. A observação visual de tais distribuições revelaram uma não continuidade das tendências observadas na camada de $0,0-0,20 \mathrm{~m}$ para a de 0,20-0,40 m, ou seja, os pontos que apresentavam maiores ou menores valores de umidade não se repetem em profundidade. De maneira geral, a camada de 0,20-0,40 m evidenciou em todas as tensões avaliadas maior homogeneidade quanto à distribuição da umidade do solo.

A observação conjunta da distribuição espacial dos atributos físicos possibilitou a identificação de três ambientes distintos, os quais podem ser manejados quanto à irrigação de forma diferenciada, constituindo assim zonas homogêneas para a realização de tal prática agrícola de maneira operacional. Uma subdivisão da área de cultivo superior a três zonas de manejo poderia inviabilizar a aplicação de tais práticas. Procedimento semelhante também foi realizado por Campos et al. (2007), ao identificarem zonas de manejo a partir da observação conjunta de mapas da composição granulométrica. Assim, para a realização do manejo de irrigação nesse estudo, foi selecionado o mapa de AD na camada de 0,20-0,40 $\mathrm{m}$, por apresentar o maior alcance $(188 \mathrm{~m})$. Ainda, a profundidade de $0,40 \mathrm{~m}$ é onde se encontra a profundidade efetiva do sistema radicular de videira (Bassoi et al., 2002).

Para a realização do manejo de irrigação diferenciado, com base nas zonas de manejo, selecionaram-se as áreas correspondentes às válvulas de derivação 1 e 2 (fileiras 1 a 10 e fileiras 11 a 20, respectivamente), conforme apresentado na figura 6 , que a presentavam três zonas homogêneas, com alto (zona 2), médio (zona 4) e baixo (zona 6) valores de AD. Em cada uma delas, foi realizada a instalação dos tensiômetros. Também se desejou que cada zona de manejo estivesse inserida em uma das subáreas definidas pela instalação dos registros de linhas para a divisão da área irrigada em cada válvula em três partes. Tensiômetros também foram instalados em mais três pontos (zona 1, 3 e 5). Nas fileiras 21 a 40, não foi aplicado o manejo diferenciado da irrrigação pela homogeneidade do atributo $\mathrm{AD}$ na camada de $0,20-0,40 \mathrm{~m}$.

Durante o ciclo de produção de 2011, foram aplicados 4,$89 ; 4,73 ; 4,73 ; 4,56 ; 4,56$; e $4,73 \mathrm{~m}^{3}$ de água por videira e 6,$30 ; 5,84 ; 5,87 ; 6,55 ; 6,52$; e $6,80 \mathrm{~m}^{3}$ de água por videira no ciclo de produção de 2012 , respectivamente nas zonas $1,2,3,4,5$ e 6 . O volume de água aplicado foi menor nas zonas de manejo que apresentaram maiores valores de umidade durante cada ciclo.

A variabilidade espacial do número de cachos de uva por planta (Figura 7) apresentou boa homogeneidade em ambos os anos. 
$0,0-0,20 \mathrm{~m}$

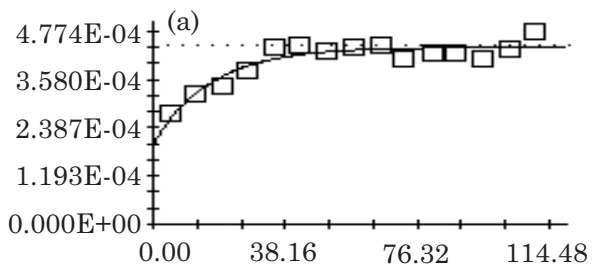

(b)
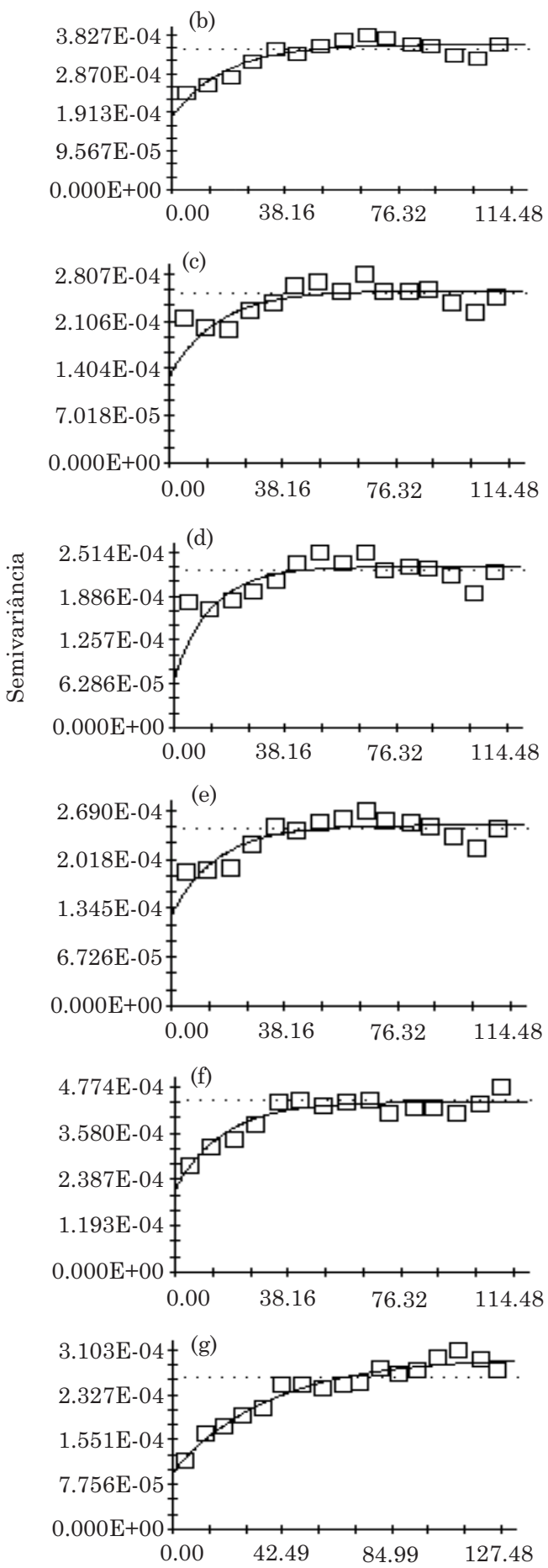

$0,20-0,40 \mathrm{~m}$

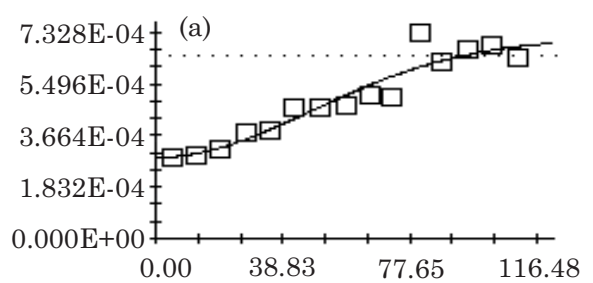

(b)
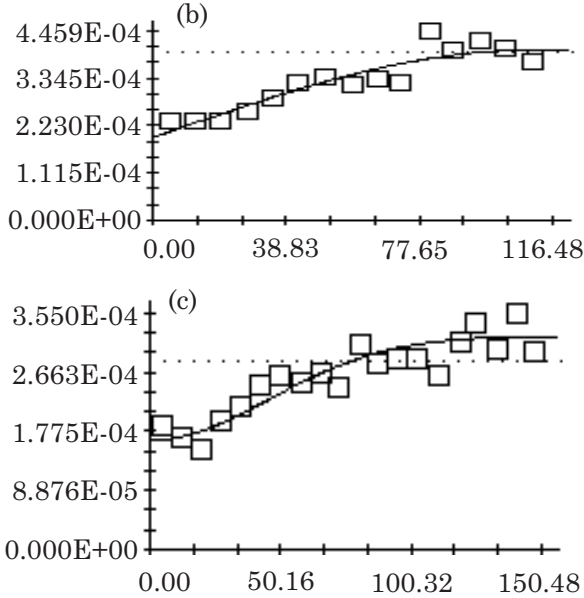

(d)
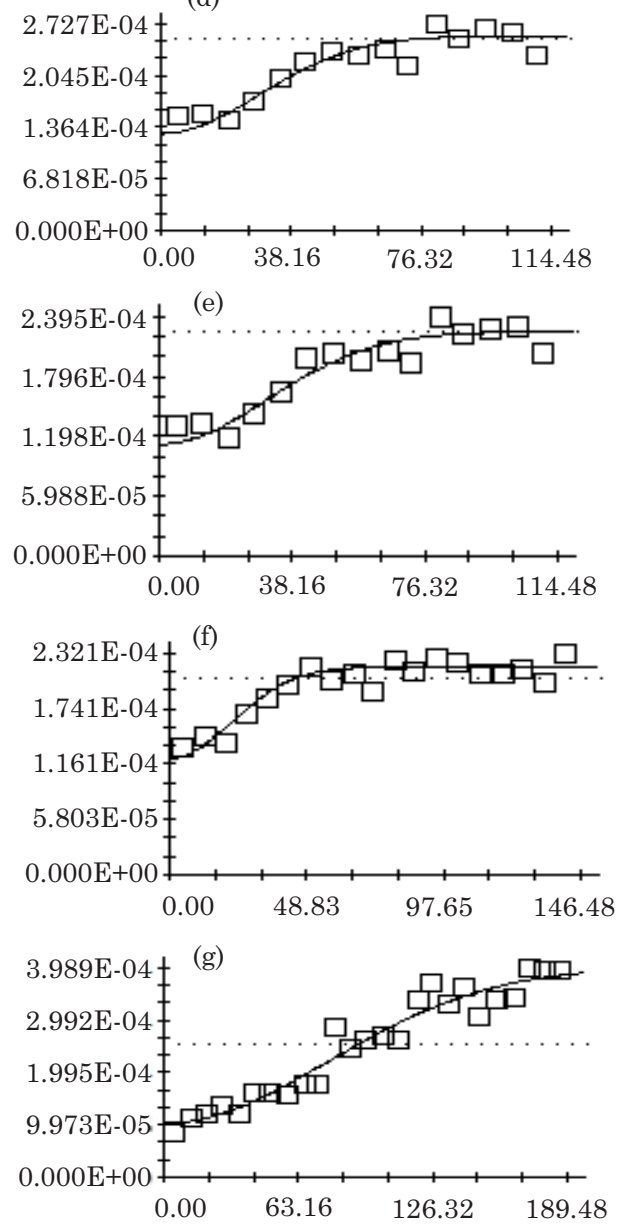

Distância, $m$

Figura 3. Semivariograma da umidade do solo à tensão de $0.006 \mathrm{MPa}$ (a), $0.010 \mathrm{MPa}$ (b), $0.033 \mathrm{MPa}$ (c), 0.06 $\mathrm{MPa}(\mathrm{d}), 0.1 \mathrm{MPa}(\mathrm{e})$ e 1.5 MPa (f) e da água disponível (g), nas camadas de 0,0-0,20 e 0,20-0,40 m. 

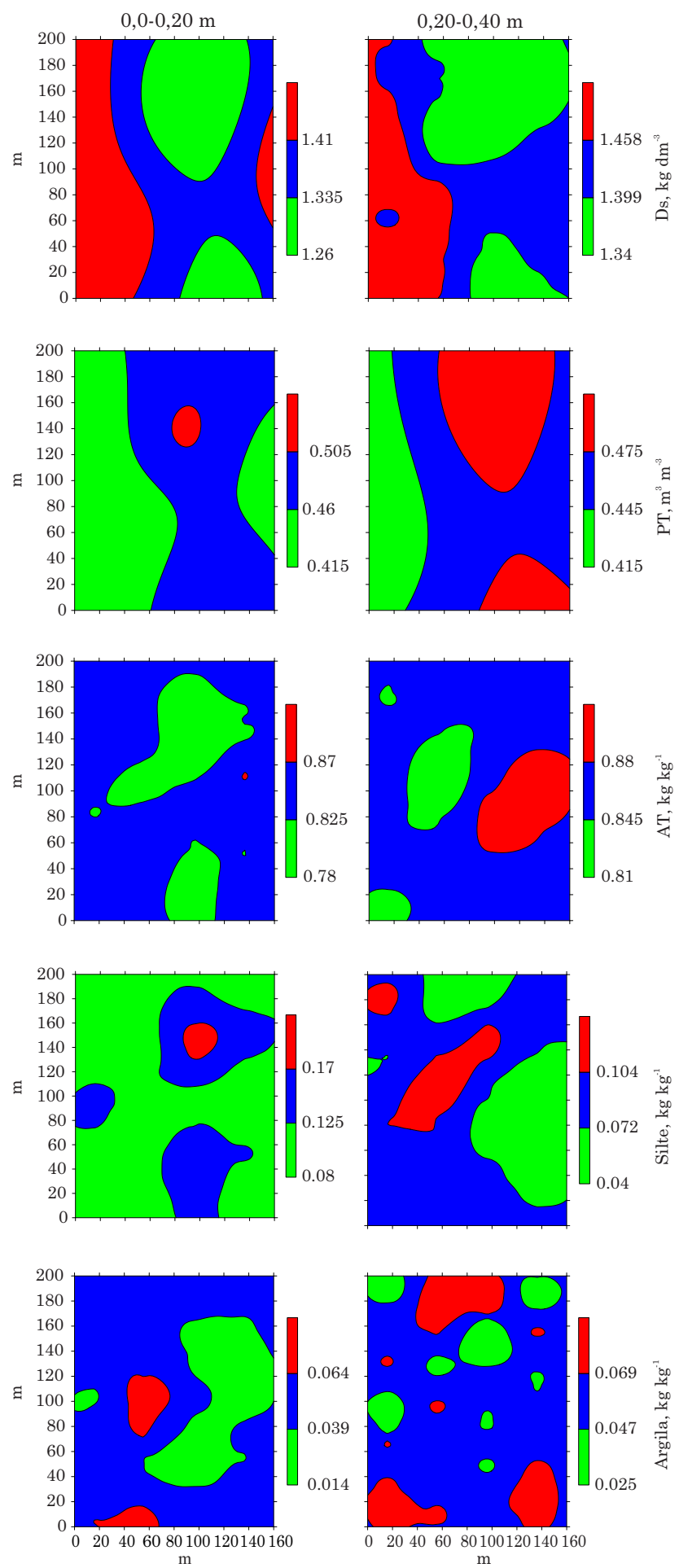

Figura 4. Mapas de zonas homogêneas da densidade do solo (Ds), porosidade total (PT), areia total (AT), silte e argila, na área experimental.
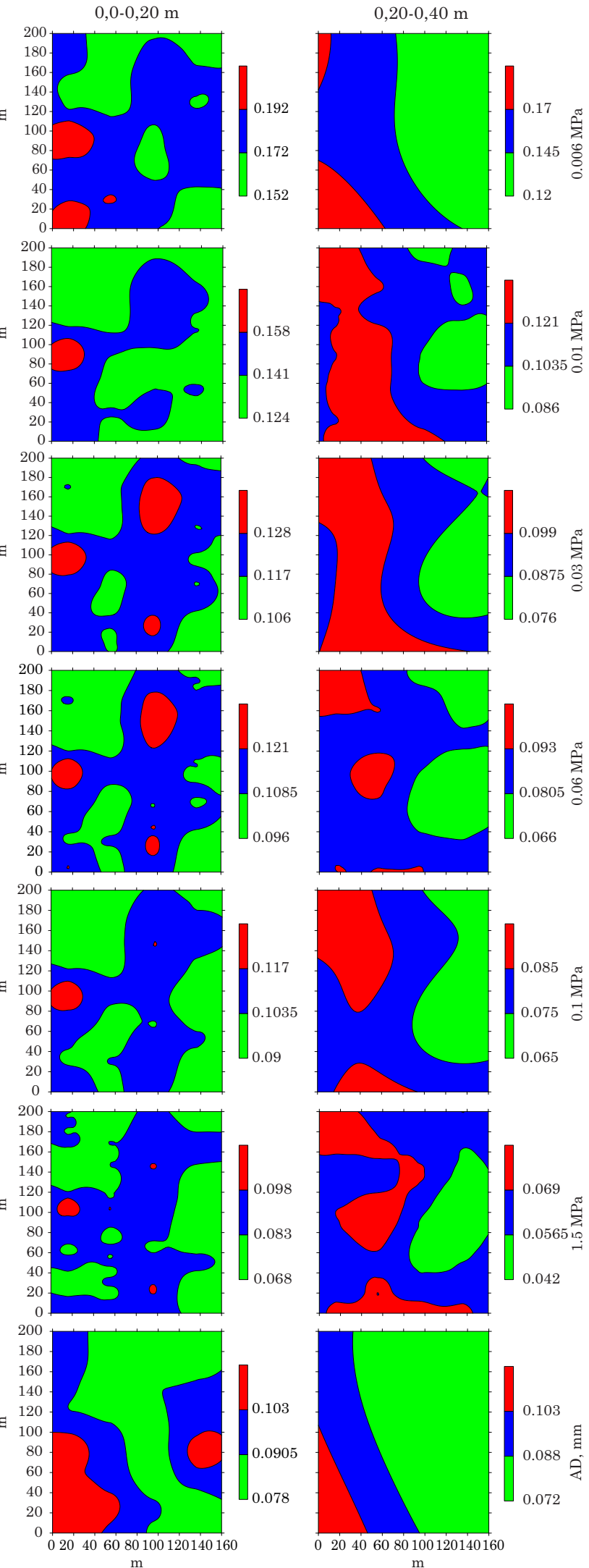

igura 5. Distribuição espacial da umidade do solo nas diferentes tensões da curva de retenção de água e da água disponível (AD), nas camadas de $0,0-0,20$ e $0,20-0,40 \mathrm{~m}$.

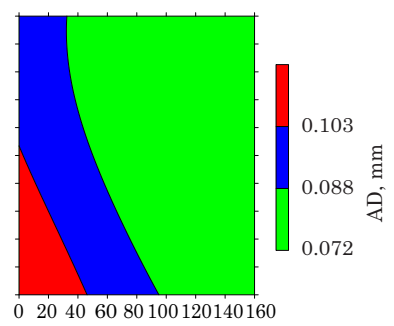




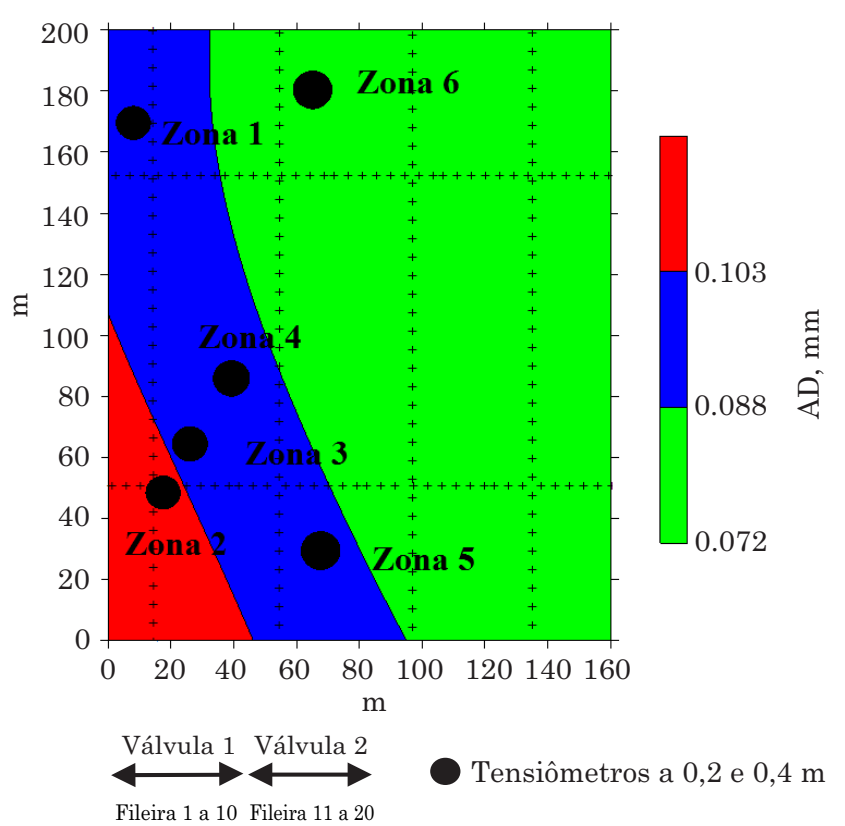

Figura 6. Zonas de manejo de irrigação determinadas, levando-se em conta as zonas homogêneas do solo e a subdivisão do sistema de irrigação.
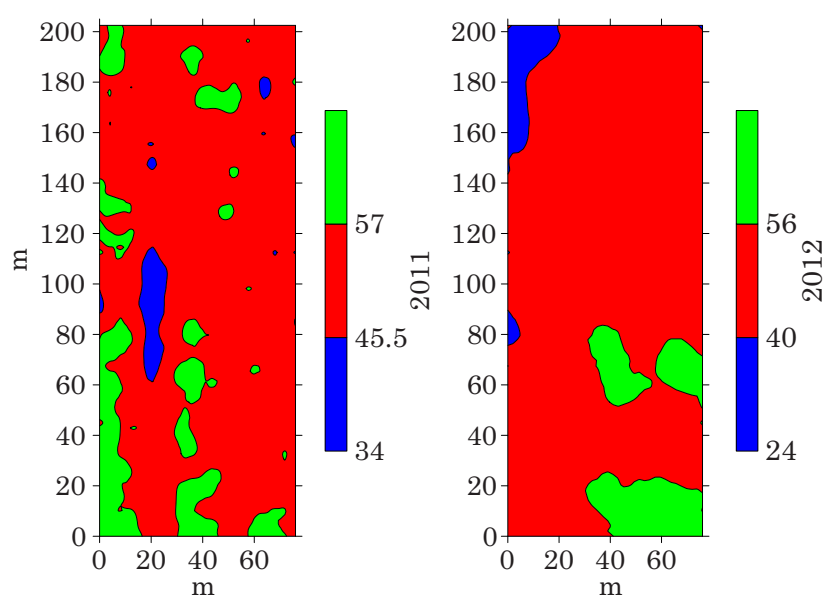

Figura 7. Zonas homogêneas do número de cachos de uva por videira em toda a área, nos ciclos de produção de 2011 e 2012.

\section{CONCLUSÕES}

1. Os atributos físicos do solo medidos em quatro transeções na área cultivada com videiras apresentaram dependência espacial de moderada a forte, nas camadas de 0-0,20 e 0,20-0,40 m. A umidade do solo e a capacidade de água disponível evidenciaram dependência espacial moderada em ambas as camadas de solo. Consequentemente, foram obtidas as zonas homogêneas dos atributos físico-hídricos.

2. A água disponível na camada de 0,20-0,40 m apresentou o maior valor de alcance de todos os atributos do solo analisados, com dependência espacial forte, e foi o atributo considerado para a delimitação de zonas homogêneas para fins de manejo diferenciado da irrigação.

\section{AGRADECIMENTOS}

À fazenda Sasaki, pela concessão da área, pelo fornecimento de dados e apoio; à rede de Agricultura de Precisão da Embrapa; e à FACEPE, pelo apoio financeiro para a realização do trabalho.

\section{LITERATURA CITADA}

ALCÂNTARA, G.R. Variabilidade espacial de características físico-químicas e condutividade elétrica aparente do solo sob plantio direto. Anápolis, Universidade Estadual de Goiás, 2010. 91p. (Dissertação de Mestrado)

AMADO, T.J.C. \& GIOTTO, E. A sua lavoura na tela. Granja, 732:38-42, 2009.

BASSOI, L.H.; GRANGEIRO, L.C.; SILVA, J.A.M. \& SILVA, E.E.G. Root distribution of irrigated grapevine rootstocks in a coarse texture soil of the São Francisco Valley, Brazil. R. Bras. Frutic., 24:35-38, 2002.

BATISTA, I.F. \& ZIMBACK, C.R.L. Análise espacial de nutrientes e produção de alface cultivada em ambiente protegido. Irriga, 15:401-413, 2010.

CAJAZEIRA, J.P. \& ASSIS JÚNIOR, R.N. Variabilidade espacial das frações primárias e agregados de um Argissolo no Estado do Ceará. R. Ci. Agron., 42:258-267, 2011.

CAMBARDELLA, C.A.; MOOMAN, T.B.; NOVAK, J.M.; PARKIN, T.B.; KARLEM, D.L.; TURVO, R.F. \& KONOPA, A.E. Field-scale variability of soil properties in central Iowa soils. Soil. Sci. Soc. Am. J., 58:1501-1511, 1994.

CAMPOS, H. Estatística experimental não-paramétrica. 3.ed. Piracicaba, ESALQ, 1979. 343p.

CAMPOS, M.C.; MARQUES JUNIOR, J.; PEREIRA, G.T.; MONTANARI, R. \& SIQUEIRA, D.S. Variabilidade espacial da textura de solos de diferentes materiais de origem em Pereira Barreto, SP. R. Ci. Agron., 38:149$157,2007$.

CARVALHO, J.R.P. \& ASSAD, E.D. Análise da precipitação pluviométrica no Estado de São Paulo: comparação de métodos de interpolação. Eng. Agric., 25:377-384, 2005.

CARVALHO, M.P.; TAKEDA, E.Y. \& FREDDI, O.S. Variabilidade espacial de atributos de um solo sob videira em Vitória Brasil (SP). R. Bras. Ci. Solo, 27:695-703, 2003.

CARVALHO, J.R.P.; SILVEIRA, P.M. \& VIEIRA, S.R. Geoestatística na determinação da variabilidade espacial de características químicas do solo sob diferentes preparos. Pesq. Agropec. Bras., 37:1151-1159, 2002. 
CENTURION, J.F. \& ANDRIOLI, I.A.P. Regime hídrico de alguns solos de Jaboticabal. R. Bras. Ci. Solo, 24:701-709, 2000 .

COELHO FILHO, M.A.; COELHO, R.D. \& GONCALVES, A.C.A. Variabilidade espacial de variáveis físico-hídricas do solo em um pomar de lima ácida tahiti, irrigado por microaspersão. R. Bras. Eng. Agríc. Amb., 5:239-246, 2001.

CURI, N.; LARACH, J.O.I.; KÄMPF, N.; MONIZ, A.C. \& FONTES, L.E.F. Vocabulário de ciência do solo. Campinas, Sociedade Brasileira de Ciência do Solo, 1993. 89p.

DELlAMEA, R.B.C.; AMADO, T.J.C.; BELLÉ, G.L.; LONDERO, G.T \& DONDÉ, R.J. Agricultura de precisão voltada à melhoria da fertilidade do solo no sistema plantio direto. In: CONGRESSO BRASILEIRO DE CIÊNCIA DO SOLO, 31., Gramado, 2007. Anais... Gramado, Sociedade Brasileira de Ciência do Solo, 2007. CD-ROM

EMPRESA BRASILEIRA DE PESQUISA AGROPECUÁRIA EMBRAPA. Centro Nacional de Pesquisa do Solo. Manual de métodos de análise de solo. Rio de Janeiro, Centro Nacional de Pesquisa de Solos, 1997. 212p.

EMPRESA BRASILEIRA DE PESQUISA AGROPECUÁRIA . EMBRAPA. Centro Nacional de Pesquisa do Solo. Sistema brasileiro de classificação de solos. Brasilia, Embrapa SPI; Embrapa Solos, 2006. 306p.

EGUCHI, E.S.; SILVA, E.L. \& OLIVEIRA, M.S. Variabilidade espacial da textura e da densidade de partículas em um solo aluvial no Município de Lavras, MG. R. Bras. Eng. Agríc. Amb., 6:242-246, 2002.

FARACO, M.A.; URIBE-OPAZO, M.A.; SILVA, E.A.A.; JOHANN, J.A. \& BORSSOI, J.A. Seleção de modelos de variabilidade espacial para elaboração de mapas temáticos de atributos físicos do solo e produtividade da soja. $R$. Bras. Ci. Solo, 32:463-476, 2008.

GOLDEN Software INC. (Golden, Estados Unidos). Surfer for Windows: Release 7.0, contouring and 3D surface mapping for scientist's engineers User's Guide. New York, 1999. 619p.

GREGO, C.R. \& VIEIRA, S.R. Variabilidade espacial de propriedades físicas do solo em uma parcela experimental. R. Bras. Ci. Solo, 29:169-177, 2005.

LIMA, J.A.G.; MENDES, A.M.S.; DUDA, G.P. \& FERREIRA, C.V. Variabilidade espacial de características físicohídricas de um Cambissolo cultivado com mamão no semiárido do RN. R. Caatinga, 19:192-199, 2006.

MACHADO, P.L.O.A.; BERNARDI, A.C.C.; VALENCIA, L.I.O.; MOLIN, J. P.; GIMENEZ, L.M.; SILVA, C.A.; ANDRADE, A.G.A.; MADARI, B.E. \& MEIRELLES, M.S.P.M Mapeamento da condutividade elétrica e relação com a argila de Latossolo sob plantio direto. Pesq. Agropec. Bras., 41:1023-1031, 2006.

MENDES, A.M.S.; FONTES, R.L.F. \& OLIVEIRA, M. Variabilidade espacial da textura de dois solos do Deserto Salino, no Estado do Rio Grande do Norte. R. Ci. Agron., 39:1-6, 2008.

MOLIN, J.P. Definição de unidades de manejo a partir de mapas de produtividade. Eng. Agríc., 22:83-92, 2002.
MORAES, S.O. \& LIBARDI. P.L. Problemas metodológicos na obtenção da curva de retenção da água pelo solo. Sci. Agríc., 50:383-392, 1993.

ORTIZ, J.L. Emprego do geoprocessamento no estudo da relação entre potencial produtivo de um povoamento de eucalipto e atributos do solo e do relevo. Piracicaba, Universidade de São Paulo, 2003. 205p. (Dissertação de Mestrado)

PIMENTEL-GOMEZ, F. \& GARCIA, C.H. Estatística aplicada a experimentos agronômicos e florestais: exposição com exemplos e orientações para uso de aplicativos. Piracicaba, FEALQ, 2002. 309p.

ROBERTSON, G.P. GS+: Geostatistics for the environmental sciences - GS+ User's Guide. Plainwell, Gamma Design Software, 1998. 152p.

SANTOS, K.S.; MONTENEGRO, A.A.A.; ALMEIDA, B.G.; MONTENEGRO, S.M.G.L.; ANDRADE, T.S. \& FONTES JÚNIOR, R.V.P. Variabilidade espacial de atributos físicos em solos de vale aluvial no semiárido de Pernambuco. R. Bras. Eng. Agríc. Amb., 16:828-835, 2012.

SILVA, E.M. \& AZEVEDO, J.A. Influência do período de centrifugação na curva de retenção de água em solos de Cerrado. Pesq. Agropec. Bras., 37:1487-1494, 2002.

SIQUEIRA, G.M.; VIEIRA, S.R. \& DECEN, S.C.F. Variabilidade espacial da densidade e da porosidade de um Latossolo Vermelho Eutroférrico sob semeadura direta por vinte anos. Bragantia, 68:751-759, 2009.

SOUSA, J.R.; QUEIROZ, J.E. \& GHEYI, H.R. Variabilidade espacial de características físico-hídricas e de água disponível em um solo aluvial no semi-árido paraibano. R. Bras. Eng. Agríc. Amb., 3:140-144, 1999.

SOUZA, L.C. Variabilidade espacial da salinidade de um solo aluvial no semi-árido paraibano. Campina Grande, Universidade Federal da Paraíba, 1999. 77p. (Dissertação de Mestrado)

SOUZA, Z.M.; MARQUES JUNIOR, J. \& PEREIRA, G.T. Variabilidade espacial de atributos físicos do solo em diferentes formas de relevo sob cultivo de cana-de-açúcar. R. Bras. Ci. Solo, 28:937-944, 2004.

STATSOFT. Statistica for Windows versão 5.0. Tulsa, 1999.

VIEIRA, S.R. Variabilidade espacial de argila, silte e atributos químicos em uma parcela experimental de um Latossolo Roxo de Campinas (SP). Bragantia, 56:181-190, 1997.

VIEIRA, S.R. Geoestatística em estudos de variabilidade espacial do solo. In: NOVAIS, R.F.; ALVAREZ V., V.H. \& SCHAEFER, G.R., eds. Tópicos em ciência do solo. Viçosa, MG, Sociedade Brasileira de Ciência do Solo, 2000. v.1, p.1-54.

VIEIRA, S.R. \& PAZ GONZÁLEZ, A. Analysis of the spatial variability of crop yield and soil properties in small agricultural plots. Bragantia, 62:127-138, 2003.

WARRICK, A.W. \& NIELSEN, D.R. Spatial variability of soil physical properties the soil. In: HILL, D., ed. Applications of soil physics. New York, Academic Press, 1980. p.319344. 
ZIMBACK, C.R.L. Análise espacial de atributos químicos de solos para fins de mapeamento da fertilidade. Botucatu, Universidade Estadual Paulista, 2001. 114p. (Tese de Livre-Docência)
ZUCOLOTO, M.; LIMA, J.S.S. \& COELHO, R.I. Correlação e variabilidade espacial de atributos químicos do solo e produção de bananeira 'Prata-Anã'. R. Bras. Frutic., 33:479-484, 2011. 